\title{
THORACIC SURGERY DIRECTORS ASSOCIATION: 1994 IN REVIEW
}

$\mathrm{T}_{\mathrm{T}}^{\mathrm{h}}$ he past year has seen continued evolution of the Thoracic Surgery Directors Association (TSDA) as a strong, active force in American thoracic surgical resident education. Current officers constituting the Executive Committee of the TSDA include Gordon F. Murray, President; John R. Benfield, President-Elect; Mark B. Orringer, Secretary/Treasurer; and Sidney Levitsky and Gordon N. Olinger, Executive Committeemen.

\section{TSDA operational guide}

A TSDA Operational Guide for Program Directors was developed and distributed by President Gordon F. Murray. This guide is an administrative manual that describes the history and organization of the TSDA and the process of credentialing, that is, accrediting thoracic surgery programs by the Residency Review Committee (RRC for Thoracic Surgery) and certification of candidates by the American Board of Thoracic Surgery (ABTS). How the program director interacts with each organization is defined, and the responsibilities of the program director are outlined in a concise and understandable format.

\section{TSDA office}

The office of the TSDA secretary is the administrative clearinghouse for the Association and maintains, among other things, an accurate current listing of all thoracic surgery programs and residents, a list of unexpected openings in residency programs, and a record of general surgery residents seeking positions in thoracic surgery programs ("late deciders"). The annual TSDA database, completed each July by the directors, provides general demographic information about the residency programs. For example, as of July 1994, of the 93 accredited RRC-approved

By prior agreement, this report is being published both in this JoURNAL and in The Annals of Thoracic Surgery.

J Thorac Cardiovasc SuRg 1995;109:1265-6

Copyright $(\mathcal{C} 1995$ by Mosby-Year Book, Inc.

$0022-5223 / 95 \$ 3.00+0 \quad \mathbf{1 2 / 1 / 6 4 4 5 8}$ thoracic surgery residency programs, $88 \%$ were either a division or section within a department of surgery, and only $12 \%$ were separate departments. Seventy-four percent were approved for 2 years, $25 \%$ for 3 years, and $2 \%$ for $2 \frac{1}{2}$ years. Sixty-two percent of programs now have separate subspecialty rotations for their residents on general thoracic surgery.

\section{Thoracic surgery residency match}

All thoracic surgery residents are now selected through a uniform, standardized National Thoracic Surgery Residency Matching Program. Another successful thoracic surgery residents' match took place this year on April 15, 1994, as candidates were selected for residency beginning in July 1996. All 93 (100\%) programs participated. Of the 197 active applicants, $140(71 \%)$ matched, and 57 (29\%) failed to match. Of the 140 residents who matched, $73(52 \%)$ got their first choice, $19(14 \%)$ their second choice, and $18(13 \%)$ their third choice. There were 146 active residency positions available. Eighty-seven (94\%) of the 93 programs had their positions filled through the match, and this included $140(96 \%)$ of the available positions. Only six programs $(6 \%)$ had unfilled positions, and these were quickly filled by unmatched resident applicants coordinated through the $\mathrm{Na}$ tional Residency Matching Program (NRMP) office.

After the match, a survey of general surgery residents who matched for thoracic surgery residency beginning in 1996 was conducted. Of 143 questionnaires mailed, $112(78 \%)$ were returned. Of those responding, 107 (95\%) thought that the match was effective in achieving its goal of providing a fair, more uniform process of resident selection. Only three (3\%) thought that they had experienced undue pressure to commit to a program outside of the match, and only two (2\%) thought that more than one program violated the spirit of the match. The number of programs at which resident applicants interviewed ranged from 1 to 21 (average 6). The 
total cost of these interviews to the applicants ranged from no cost up to $\$ 16,000$ (average $\$ 3,295$ ). Only $15(13 \%)$ of the respondents preferred to keep the timing of the match as is (approximately 21/2 years before the start of thoracic surgery residency); $89(80 \%)$ preferred delaying the time of the match to 1 year before completion of general surgery residency; and only five (4\%) preferred an earlier match than is currently used. At the April 23, 1994, TSDA meeting, in response to this clear preference for a later match, by unanimous vote, the directors decided that there will be no match in 1995 . Instead, applicants applying for thoracic surgery residency beginning in July 1997 will be matched in June 1996, approximately 1 year before the start of their training. This will allow the residents to make their career decision after having had more opportunity to experience thoracic surgery on rotations during general surgery residency. Conversely, the program directors will be selecting residents from a more mature candidate pool and about whom letters of evaluation will be more meaningful.

To further streamline the matching process, the TSDA has developed a Thoracic Surgery Residency Universal Application form. Residents applying to multiple programs will be required to complete only one application, which will be acceptable to all programs. General surgery residents contacting the National Resident Matching Program office will receive both the universal application form and the application for the match. The thoracic surgery residency match has been characterized by integrity and fairness on the part of applicants and directors alike, and the TSDA takes considerable pride in the success of this effort on behalf of our resident applicants.

\section{TSDA Residents Research Award}

Each year, a certain number of the abstracts accepted for presentation at the scientific program of the annual meeting of the Society of Thoracic Surgeons are eligible for the Residents Research Award, which acknowledges the primary role of the resident in the project. These abstracts are graded and ranked by the Executive Committee of the TSDA, and the winner is the recipient of an award supported by a generous grant from Medtronic, Inc., Minneapolis, Minnesota. The Fourth TSDA Residents Research Award was presented at the January 29,1994 , TSDA meeting in New Orleans to R. Barry Hird, MD, for his paper entitled, "The Direct Effects of Protamine Sulfate and Heparin Upon
Myocyte Contractile Function and Beta-Adrenergic Responsiveness" which resulted from his research in the Division of Thoracic Surgery at the Medical University of South Carolina where Fred A. Crawford, $\mathrm{MD}$, is program director.

\section{Thoracic surgery curriculum}

At its January 31, 1994, meeting in New Orleans, the directors participated in a program organized by Dr. Ronald Elkins, Chairman of the Program Committee, entitled, "Is the OR Driving Resident Education?" Participants in this program were Drs. Alexander S. Geha and Adnan Cobanoglu, who discussed the thoracic surgery resident workload, and Drs. Fred L. Grover and Hartzell V. Schaff, who discussed their views as to whether the thoracic surgery resident operative experience is too excessive. The data presented provided a basis for an open discussion among the directors, which emphasized the need to focus upon educational goals rather than service alone in our residency programs. As the need for applying traditional principles of education to the thoracic surgery curriculum was stressed, however, there was also an awareness that care must be taken not to focus only upon the measurable aspects of the educational process, as these may not necessarily reflect a resident's surgical ability.

The TSDA Curriculum Committee now cochaired by Drs. Stanton P. Nolan and Robert R. Salley, moved forward with its ambitious timetable of completing by the end of the calehdar year development of a formal Comprehensive Thoracic Surgery Curriculum to serve as a basis for study and clinical activity during the thoracic surgery residency. The charge of this committee is supported by the ABTS (Drs. Fred A. Crawford and William A. Gay, liaison representatives) and the RRC for Thoracic Surgery (Drs. Joseph I. Miller, Jr., and Robert L. Replogle, liaison representatives). Their preliminary plan calls for the curriculum to encompass approximately 13 broad topics that define the scope of thoracic surgery. The proposed curriculum format will divide each subject into four basic elements: the unit objective, learner objective, unit content, and required clinical skills. Broad input from many program directors will be sought in the development of this curriculum. Once the curriculum has been defined, the challenge ahead will be how to best implement it.

Mark B. Orringer, $M D$ Secretary/Treasurer 